\title{
DIE BEGINSEL IN ART. 30 K.O.
}

\section{PLAASLIKE VRYHEID EN VERANTWOORDELIKHEID}

\author{
Prof. B. Spoelstra
}

\section{Interaksie tussen die politieke en kerklike bestel}

Ons projekteer dikwels ons ideale as werklikhede. So gee ons dikwels op grond van die beginsel van ,soewereiniteit in eie kring" voor dat die kerklike selfstandigheid en onafhanklikheid van die sosiale en politieke werklikhede bestaan en behou moet word. Dit kan soms die geval wees, maar in werklikheid word die kerklike struktuur en praktyk deur kontemporêre opvattings en gebruike gemaak. So het die Rasionalisme en Liberalisme die Kerkordes van De Mist (1804) en van Koning Willem I (1816) veroorsaak en opvattings oor staatstruktuur is vir kerkstruktuur gebruik.

Ons eie SA kerklike situasie en inrigting is grootlik beĩnvloed deur ons geskiedenis. Die Afrikaner se stryd om vryheid en onafhanklikheid teen die Engelse imperialisme, die Europese rassisme waarmee binne een politieke bestel tussen wit en swart onderskei is, die werklikheid van talle volke en die na-oorlogse verskuiwing van imperialisme na internasionalisme, het kerklike strukture gevorm. Sommige kerkstrukture probeer die eie Afrikaanse „volks"gebonde patroon behou, of die rasbeginsel of die volkereverskeidenheid of die idee van een groot oop geïntegreerde samelewing eerbiedig. Dit sou dwaas wees om die huidige NG Kerkfamilie van ras-bepaalde "kerke" of die Algemene Sinodale verband in die GKSA onafhanklik van die sosio-politieke bestel te bestudeer. Daarom moet ons die Kerkorde ook in die lig van die volle werklikheid van die vroeë $16 \mathrm{de}$ eeu bestudeer.

Die politieke en/of kerklike bestel kan globaal beskou een van twee vorme aanneem. Die eerste sisteem kom neer op sentralisasie, eenheid en monisme. Administrasie is maklik en effektief wanneer dit per slot van sake in die hande van een koning, keiser, pous, parlement of sinode gesentreer is. Hierdie sisteem vra „eenvormigheid" en "dieselfde gedragslyn" dwarsdeur die kerkverband. Hierdie motivering word dikwels aangevoer om sinodes besluite te laat neem of soms om 'n ander te verhoed om iets nuuts, vreemds of anders (maar nie noodwendig on-Bybels nie!) te doen. Dikwels het die instansie wat die besluit by die sentrale pool probeer verkry, self nog niks oor die saak besluit nie. Die rede vir die versuim is dat die voorstel ,in algemene belang" sou wees en daarom moet 'n ander instansie daaroor oordeel.

Uiteraard kom hierdie benadering veral voor by kerkgemeenskappe wat in 'n land en staatsbestel leef soos dié van Suid-Afrika. Ons SA stelsel is op Engelse model monisties en gesentraliseerd geskoei. Let egter op hoedat die sentralisasie vryhed by die plaaslike pole wegneem en die plaaslike of "mindere" pole van verantwoordelikheid onthef. Daar word vrywillig van die eie vryheid afstand 
gedoen en na die sinode gekyk om verantwoordelikheid te neem. (Die sinode ontwyk dikwels weer sy plig om te besluit deur ,studiedeputate" te benoem).

Die teenoorgestelde van 'n monistiese sisteem is een van desentralisasie en pluralisme. Daarin het individue, kleiner gemeenskappe, munisipaliteite, korporasies, verenigings ens. die reg om hulleself vry te bestuur en te bevorder, solank dit nie met die algemene belange in stryd raak nie. Dit is die beginsel van nie-inmenging in die "huishoudelike" sake van 'n ander, behalwe wanneer die reg geskend word. Desentralisasie waarborg die maksimum vryheid en stel elkeen plaaslik verantwoordelik om sy eie roeping te verwesenlik. Die ander kan slegs inmeng wanneer die reg, d.w.s. die verantwoordelikheid aan die Wil van God, oortree word.

Die beginsel van plaaslike vryheid en verantwoordelikheid is eie aan die Nederlandse staatsbestel en aan die Gereformeerde Kerkorde van die $16 \mathrm{de}$ en $17 \mathrm{de}$ eeu. „Op meerdere vergaderings moet alleen sake behandel word wat nie in die minder vergaderings afgehandel kan word nie ..." (art. $30 \mathrm{KO}$ ). Die artikel volg net nadat die samekoms van meer kerke gestel is. Dit wil dadelik die bevoegdheid en magte van die byeenkoms van meer kerke so beperk dat op plaaslike vryheid en verantwoordelikheid geen inbreuk gemaak sal word nie. Die kerke het pas in die 16 de eeu genoeg van Roomse en Spaans-imperiale sentralisasie en monisme ervaar en wou dit nie van "meerdere vergaderinge" weer 'n keer ondervind nie.

\section{Paralelle tussen kerklike en politieke bestel}

Die Vroeë Christelike Kerk het in baie (plurale) gemeentes die een liggaam van Christus sigbaar gemaak. Die eenheid (monisme) in Christus is sigbaar in 'n pluraliteit van kerke in so ver hulle verantwoordelik die Woord gehoorsaam en in een geloof vas staan.

Daarteenoor is die Romeine Ryk gesentraliseerd en monisties vanuit Rome (later Konstantinopel) deur een keiser geregeer. Die politieke monisme word gedurende die Middeleeue die ideaal vir die kerklike inrigting totdat die primaat van die biskop van Rome aan die begin van die $13 \mathrm{de}$ eeu in Innocentius III kerk en wêreld domineer. Die vraag of die pous of die konsilie (sinode) die sentrale pool verteenwoordig, verander niks aan die sisteem nie. Die sisteem is gesentraliseerd, monisties, ekumenies en wars van alle pluralisme, plaaslike vryheid en verantwoordelikheid.

Tydens die Reformasie het die Ryksidee begin wyk vir die idee van onafhanklike vrye nasionale volkstate. Onmiddellik kry ons ook die idee van eius regio cuius religio, 'n stads- of volkskerk van Genéve, die kerk van Christus konkreet aanwesig in die vergaderde Godsvolk. Gedurende die Reformasie bestaan die kerke baie lank as independente stadskerke. Eers in 1559 in Frankryk en 1571 in Nederland aanvaar plurale kerke samewerking in sinodale verband. Let egter goed daarop: Hulle is nie daarmee gesentraliseer en in 'n monistiese „,kerkverband" opgelos nie. Dat hulle in sinodale verband plurale, selfstandige en komplete kerke bly, bepaal die plek van art. 30 net na 29 in die $\mathrm{KO}$. 
In die na-oorlogse wêreld het die monistiese wêreldidee die ou Europese Ryksidee vervang. Sosialisme, Kommunisme en Kapitalisme het belang by die administratiewe voordele van 'n gesentraliseerde wêreld. Dit stel hom onversoenbaar op teen alle afsonderlike ontwikkeling, die onafhanklikwording van SA swart nasionale state. Is dit nie opmerklik nie dat net 'n baie kort kop agter, monisme ook die gees agter kerklike beweginge word nie? Die "kerke" is op toer met die ,eenheid van die kerk", ekumenisme, kerkvereniging, konfessionele indifferentisme en pragmatisme as norm.

Sentralisasie en monisme glo dat die geheel groter, belangriker en beter is as elke saamstellende deel. Rome het daarom alle dissenters soos die Waldense, Katare, Protestante terwille van die eenheid probeer uitwis. Die monisme duld geen plaaslike vryheid en verantwoordelikheid nie, maar eis eenheid as eenvormigheid. Die Protestantse wêreld het in die 18de eeu begin om die begrippe ,kerk" en „staat" al meer abstrak as ,a mental construction or juristic creation, i.e. a legally created capacity of sustaining rights and duty which are also legal creations themselves" te verstaan ${ }^{1}$. Hierdie abstraksie ,kerk" het in baie opsigte die monistiese pool geword wat die pous vervang het.

Dit val ' $n$ mens op hoe minagtend en fanaties vandag alle kerklike pluralisme bejeën en selfs as „,sonde" bestempel word. Ek meen dat in die Afrikaanse kerklike situasie die nasionaal-monistiese faktor altyd sterk in NG kringe na vore gekom het. Ek kan my omtrent nie 'n geleentheid herinner waar 'n NG dominee 'n Gereformeerde ontvangs of vergadering moes groet, waar hy dit nie oor die eenheid wat die Gereformeerdes eintlik in die NG kerk moet soek nie, gehad het nie. Daarteenoor het die baie uitsprake van Gereformeerde Sinodes, veral tot en met ongeveer 1942, dat die sinode nie hierin of daarin aan die kerke wil voorskrywe nie (vgl. bv. ampsgewaad, kollektes, salarisskale, Skrifberyminge ens.), my oortuig dat die pluralisme en beginsel van plaaslike vryheid en verantwoordelikheid deur die Geref. meerdere vergaderinge gehandhaaf is. Ek is egter bereid om toe te gee dat ek dit nie sonder meer vir vandag sal wil probeer aantoon nie. Ek glo ook dat die pluralisme nie meer gelykelik met eenheid vandag as waardevol nagestreef word nie. In baie opsigte het slegs die eenheid en monisme as die waardevolle gekristalliseer sodat die beginsel van plaaslike vryheid en verantwoordelikheid daarvoor moet wyk.

\section{Die Calvinisme en plaaslike vryheid}

Die grondbeginsels en formuleringe van die Dordtse Kerkorde van 1619 kom dikwels woordeliks uit boek IV van Calvyn se Institusie. Waar hy daar handel oor kerklike regering, gesag en strukture straal die heerlike vryheid wat die Woord van God gebring het en waarsku hy op sterkte van Gal. 5:1 v. dat die christene hulle nie weer deur kerklike gesagsdraers of sinodes onder 'n juk van diensbaarheid moet laat bring nie. Calvyn lê ook daar besonđere nadruk op die vryheid van gewete van elke christen. Kerklike ampsdraers en vergaderinge moet ook dit respekteer en daarom verdraag- 
saam wees wanneer daar in die nie-essensiële leerstukke afwykende opvattings by christene sou bestaan. Die wese en die eenheid van die kerk, waarvoor hy deur sewe seë sal gaan om dit te bewerkstellig, is geleë in die gehoorsaamheid aan die Woord en Gees van God en daadwerklike onderskrywing en handhawing van die Belydenis.

Wanneer die Reformasie 'n aanvang neem, bestaan onder die verskillende Germaanse volksgroepe, nog die samelewingsorganisasie wat plaaslike vryheid en verantwoordelikheid toeken aan families, stamme, feodale leenhere met diegene wat hulle vrywillig onder sy beskerming stel, gildes, broederskappe ens. Koning en volk is kontraktueel verbind. Pas het die beweging vir nasionale vryheid in die 15 de eeu na vore gekom, of die ideaal van 'n absolute gesentraliseerde vors wat nie langer deur die reg gebind word nie, kom na vore. Machiavelli het in sy „Die Prins" die filosofie neergelê dat die belang van die ,staat" (die prins) gaan bo alle regte uit. Wanneer die Franse koning dus sy absolute koningskap wil vestig, wil hy die pluralisme en plaaslike gesag en vryhede van die Hugenote uitwis. Met daardie doel voor oë loods hy die moord in die St. Bartholomeusnag in 1572 op Hugenoteleiers. Dit word opgevolg met die herroeping van die Edik van Nantes 1685. Hierdie brutale minagting vir die reg wat plaaslike vryheid en verantwoordelikheid waarborg, het verreikende gevolge gehad en in 'n sekere sin regstreeks gelei tot die Franse Rewolusie van 1789. Dit is interessant dat die voorsitter van die Nasionale Vergadering in Parys die seun was van ' $n$ Hugenotepredikant uit Nimes.

Calvyn se opvolgers het na die St. Bartholomeusnag met alle mag die beginsels van regssoewereiniteit en plurale vryheid teen die monistiese staatsabsolutisme opgewerp. Hottoman met sy FrancoGallica handhaaf op grond van die konstitusie die reg en wet van elke korporasie of lewensverband teen staatsabsolutisme. Die konstitusie waarborg die heerskappy van die reg en nie van een of ander persoon of struktuur nie. Mense, wie ook al, is aan die reg gebonde. Beza wys met sy De jure Magistratum op die plig van die mindere owerhede om die reg te handhaaf teen owerhede wat hulle regsbevoegdheid oorskry. Dit sluit regstreeks aan by Calvyn se beginsel van die reg van die volk om hulle teen 'n owerheid te verset onder leiding van die mindere magistrate. Die gedagte was dat die "staat" gevorm word deur 'n kontrak wat tussen God, koning en volk aangegaan word. Die volk bly die koning getrou wat aan die reg getrou bly. Op hierdie selfde beginsel het Cromwell gedurende die 17de eeu teen die Engelse koning se monisme opgetree. Nog sterker kom S. J. van Brutus (skuilnaam vir Philippe du PlessisMorné en Hubert Lanquet) in $\mathbf{1 5 7 9}$ met die Vindiciae Contra Tyrranos na vore en verdedig daarmee die reg wat die Nederlande hét om teen Philips II van Spanje in oorlog te tree.

Die Nederlande het hulle verset daarop gebaseer dat hulle soewerein hulle nie beskerm nie, maar inteendeel hulle vervolg en hulle reg om die Here ooreenkomstig sy Woord te dien ontneem. In die Plakkaat van Verlatinge van 1581 stel hulle hulle saak as mense "who confess the course of liberty, civil and religious" 2 (P. J. Loots 
a.w.p. IV, ha. E. Baker: a Hugenot theory of politics in church and state). Die Vindiciae sê dat die volk in natuurlike gemeenskappe en veelsoortige korporasies leef (pluraal) en dat elkeen so die locus van sy eie wette en regte is. Daarmee is die beginsel van plaaslike vryheid (desentralisasie) gedefinieer teenoor die absolutistiese monisme van die Spaanse koning.

Calvyn het die ordinatio Dei as uitgangspunt geneem. Die wil van God bepaal die eie roeping vir elke mens, samelewingsverband en struktuur. Predikante is daarom aan staatswette onderworpe terwyl politieke owerhede weer aan die Woord van God onderworpe bly. Daar is dus 'n meervoudige (plurale) roeping tot verantwoordelikheid selfs in 'n stadsbestuur. Hierdie beginsel het hy sterk gehandhaaf teen die gangbare ius patromatus in sacra van die corpus christianum. Sy stryd om die geestelike regering van die kerk te onderskei van die natuurlike burgerlike regering, is duidelik op die beginsel van pluralisme, plaaslike vryheid en verantwoordelikheid aan die Wil van God gebore.

Later praat A. Kuyper van die beginsels van soewereiniteit in eie kring, moontlik onder invloed van die Griekse outonomie-begrip. Die Wysbegeerte van die Wetsidee leer later dié inherente wetmatighede in strukture soos volk, wetenskap, kerk, staat ens. en verdedig daarmee 'n plurale opset, sodat een nie deur die ander oorheers moet word nie. Ons kan op die besware teen hierdie beginsels nie ingaan nie. Dit onderstreep egter dat die Calvinisme sowel as neoCalvinisme die beginsel van pluralisme ondersteun het.

Die groot beginsel van Calvyn is dat die Skrif die vryheid van die mense teenoor die magte van herders, kerkrade en sinodes waarborg. Bo die gesag van enige kerklike struktuur of outoriteit staan die gesag van God in die Skrif wat persoonlike en plaaslike vryheid waarborg (vgl. Institusie IV, $\mathbf{x x}, 31$ en art. $31 \mathrm{KO}$ ). Daarvolgens erken Calvyn die reg tot selfbepaling en selfverwesenliking volgens eie aard en volgens eie verantwoording aan die Wil van God. Die reg kom ook elke onderskeie groep en korporasie toe. Selfs die leer, kerkinrigting en seremonies sal t.o.v. tyd, plek en mense verskil en dan moet dergelike groepe nie veroordeel of op grond van die pluraliteit misken word nie. Calvyn aanvaar derhalwe die pluralisme as normaal by kerke, volke ens. sonder dat hy daarmee die essensiële eenheid uit die oog verloor.

Die invloed van Calvyn word regstreeks in die Franse KO van 1559 gesoek. Die opmerklike daarin is ook dat elke plaaslike kerk sy eie regering het deur dienaars wat aan God vir hulle diens verantwoording doen. In sy Institusie lê hy nadruk op die feit dat elkeen slegs dienaar kan wees waar hy aan 'n plaaslike kerk verbonde is. Nietemin maak die Franse KO ook voorsiening vir samewerking van kerke in sinodes.

Die opmerklike hier is dat die begrip ,,sinode” ook vir tweërlei opvatting vatbaar is. Eerstens kan die sinode as 'n eie en nuwe regspersoonlikheid, d.w.s. as 'n eenheidsorganisasie of monistiese struktuur, verstaan word waartoe die kerke afvaardig. Dit is egter ook moontlik om 'n sinode vanuit 'n plurale oogpunt te beskou. In 
daardie geval is die sinode 'n "samekoms" of konvent van plurale kerke wat ter sinode besluite neem. Die subjek vir hierdie besluite is dan nie die enkelvoud sinode nie, maar die plurale kerke wat in sinode saamgekom het. Dit is ongetwyfeld duidelik dat veral in die Nederlandse kerkregtelike ontwikkeling die "meerdere vergaderinge" oorspronklik nie as strukture nie, maar as geleenthede vir die kerke in die meervoud beskou was, waar die kerke tot besluite kon geraak.

\section{Die Nederlandse kerkinrigting 1568-1619}

Sedert die Reformasie het die een kerk van Christus in Nederland in verskillende kerke (gemeentes) - sommige selfs vlugtelingskerke buitekant Nederland - na vore gekom. Daar was tot 1571 geen organisatoriese band ('n eenheid) nie. Tog was daar al die tyd die eenheid in Christus, $n l$. die eenheid in geloof op die Woord en daarom eenheid in belydenis. Die kerk is vanuit Christus gesien streng monisties en „monargaal”, maar waar dit sigbaar word sterk pluraal en Kuyper noem dit selfs „demokraties” (A. Kuyper: Traktaat der Reformatie der Kerken, p. 7). In hierdie verband moet ons ook onthou wat P. J. Loots uit 'n gesprek met prof. Vollenhoven aanhaal (a.w.p. 60) nl. dat die gedagte nooit was dat die kerk van Christus oorspronklik een sigbare monistiese organisatoriese eenheidspatroon sou vorm nie. Indien kerklike eenheid 'n eenheid van organisasie soos 'n Ryk moes beteken, sou dit inhou dat dit ook net een kerktaal, soos in Latyn (of Engels?) moet besig. Loots sê dat Vollenhoven beweer dat "die kerk basies op 'n gedesentraliseerde grondslag georganiseer is en van onder af verwyderde kerkverband soek en vind".

Hoewel Latyn destyds vrywel algemeen gebesig kon word, het Genéve nooit na organisatoriese eenheid met Frankryk, Nederland, Duitsland of Engeland gesoek nie. Daarteenoor het kerke in naburige verbondenheid, geografies, kultureel en omstandigheid bepaald, na samewerking in sinodale verbande gesoek. So het in 1571 die Nederlandse kerke met inagneming van Franssprekende Waalse kerke te Emden tot 'n ooreenkoms oor kerklike samelewing geraak. Daarin is egter ook weer die pluralisme eerbiedig. Die Waalse kerke kon 'n eie klassis onderhou en ook die Franse Geloofsbelydenis onderskryf. Die samewerking het nie eenvormigheid veronderstel nie.

Reeds die konvent te Wezel in 1568 het nadruk daarop gelê dat die eerste natuurlike assosiasie van die plurale kerke in die klassis die belangrikste samekoms van die kerke is. Hoe nader aan die plaaslike kerk, hoe groter is die agenda en belangriker die werk vir die kerke. Die beginsel in art. $30 \mathrm{KO}$ wil hierdie verantwoordelikheid verseker. Selfstandige plaaslike kerke moet mekaar vir goeie Skrifgetroue kerkregering ondersteun - nie om 'n nuwe kerkstruktuur te vorm nie, maar met die oog daarop dat elke plaaslike kerk ware kerk sal wees (art. $29 \mathrm{NGb}$; vgl. art. 41 en $44 \mathrm{KO}$ ). Die konfederatiewe band van plurale kerke in klassis (sinode) is daarom nie opsioneel nie. Dit is noodsaaklik en plig om te verseker dat God se Woord die kerkregering bepaal. Die verband kom daarom vrywillig tot stand (Wezel, I, 6.7). Die Konvent van Wezel neem 
egter uitdruklik as basis van verstandhouding dat die „vrijheid der kerken" nie deur sinodale voorskrifte aangetas mag word nie om „tyrannie" en "twist" te weer (Wezel I, 9; vgl. II, 3; IV, 5.7.9, VIII, 14). Die kerke het dus t.o.v. die sinodes dieselfde vryheid as wat die gelowige t.o.v. die ouderling het. 'n Ouderling het ook "geen het minste gezag of vrijheid om te heerschen" (Wezel, IV, 7).

Wanneer die Nederlandse Kerke op grond van die beginsels en ooreenkoms te Wezel, nog tydens die Spaanse besetting, buite Nederland te Emden 'n ooreenkoms oor samewerking in die kerkregering in 1571 aangaan, stel hulle hierdie beginsel van vryheid en verantwoordelikheid heel vooraan: een kerk sal nie oor 'n ander kerk en een dienaar nie oor ' $n$ ander dienaar enige heerskappy voer nie. Art. 30 en art. $84 \mathrm{KO}$ is dus ook prinsipiëel verwant.

Die kerke het afgevaardigdes met mandaat en bevoegdheid voorsien om met die ander kerke so 'n kerkordelike ooreenkoms aan te gaan, mits die besluite nie sou bots met die Skrif en Belydenis nie ${ }^{3}$. Die kerke bly dus die handelende regspersone en hulle vrywillige toestemming maak die samekoms en sinode (klassis) moontlik ${ }^{4}$. Hier kom dus 'n combinatio ecclesiarum en nie 'n unio eccles. siarum soos by Rome tot stand nie .

Die Nederlanders se sin vir vryheid en eie verantwoordelikheid, reg tot selfbeskikking en selfstandige roepingsvervulling het hulle baie skoorvoetend die kerkordelike ooreenkoms by Emden 1571 laat aangaan. Hulle selfstandigheid, vryheid van gewete en vryheid tot eie verantwoordelikheid het swaar geweeg ${ }^{8}$.

Ook die ander been van art. $30 \mathrm{KO}$, nl. dat net kerklike sake op kerklike wyse behartig word, word deur Emden reeds toegepas. Hoe groot die nood, hoe ernstig die vryheidsstryd teen Spanje, die kerke het die Prins van Oranje se versoek om te help om huursoldate te bekom, afgewys.

Die beginsel van plaaslike vryheid en verantwoordelikheid wat in art. $30 \mathrm{KO}$ beliggaam word, is op hierdie heel eerste Sinode geformuleer. Slegs sake wat nie op 'n "meerdere" afgehandel kan word nie of wat al die kerke gelykelik raak, mag na „versamelinghe alle Nederlandse Kercken" gestuur word (Emden Art. 7-9, Bylae II, 3-1; III, 1).

Tegelyk in nou verband met die beginsel in Art. 30 formuleer Art. 31 dat slegs besluite wat nie met die Skrif, Belydenis of Kerkorde bots nic, sal van krag wees. Daarmee word eksplesiet die vryheid van die gelowiges en kerklike instellings teenoor die samekomste van ouderlinge en/of kerke bely. Hulle vryheid word deur die Skrif bepaal. Tegelykertyd lê daarin opgesluit dat die kerkvergadering in sy besluitneming hom aan die Woord van God moet verantwoord. Tegelyk het elkeen die reg om hom teen die kerklike besluit op grond van die Skrif (Belydenis en Kerkorde) te ver antwoord.

Hierdie stelsel van Gereformeerde kerkregering wat in die Dordtse Kerkorde van 1619 sy beslag kry, korreleer grootliks met die Nederlandse regeringstelsel wat uit die vryheidsstryd teen Spanje gebore word. Die reg het vryhede, verantwoordelikhede en self- 
standige pligvervulling vir gildes, broederskappe, universiteite, gemeentes (munisipaliteite), provinsies, ens. gewaarborg. Elkeen het intern sy eie sake bestuur, sy eie reg gespreek. "There are inponderable values in each college which cannot be properly understood or judged except by the members of that body" ?. Elke gemeenskap wat homself so self regeer het, kon ook weer assosiasies met ander soortgelyke assosiasies aangaan. Elke groep het die reg om homself te beskerm en te bevorder solank dit nie met die algemene belang bots nie ${ }^{8}$. 'n Mens kan dus beweer dat die Gereformeerde Kerkinrigting in die Dordtse Kerkorde van 1619 dieselfde beginsels van plaaslike vryheid deur regsoewereiniteit en verantwoordelikheid bevat as wat in die destydse politieke situasie gegeld het. 'n Mens kan 'n parallel aantoon tussen die selfstandige gemeente (munisipaliteit) en kerk (gemeente), die provinsiale State en partikuliere sinodes, die State Generaal en die nasionale Sinodes.

Die Nederlanders wat teen Roomse en Spaanse monisme en sentralisasie geveg het, het hulle sin vir vryheid op grond van die reg ook op die Afrikaner oorgedra. Ek het iewers 'n aanhaling uit Bancroft gelees: „The fanatic for Calvinism was a fanatic for liberty, for the moral warfare for freedom, his creed was a part of his army." Die motief lê regstreeks agter die Groot Trek, die Republieke, die Afskeiding van 1859 ens. Ons volksontwikkeling kom uit ' $n$ bedeling waarin die Nederlandse State Generaal die bestuur van die nedersetting aan die Kaap deur 'n Oktrooi aan 'n Handelsmaatskappy oorgelaat het. Die wyse waarop die HOIK die bestuur uitgeoefen het, het verder die sin vir plaaslike vryheid en verantwoordelikheid oor geslagte heen gevorm en ingeskerp. In die 19de eeu het die inslag vierkantig gebots teen die Engelse opset van sentralisasie, monisme en sentrale koninklike of parlementêre beheer.

Het ons in die 20ste eeu grootliks by hierdie gesentraliseerde monistiese siening aangepas en ons sin vir plaaslike vryheid en verantwoordelikheid verloor? Lei dit na toenemende sinodale, of "teologiese" - ekspert - kerkregering selfs vir die gewone alledaagse gang van die plaaslike kerk? Het plaaslike kerke en klassisse nog die moed om sake te beslis in die lig wat hulle het - of het 'n gees van afhanklikheid en onselfstandigheid posgevat?

Indien die vrae positief beantwoord word, het ons kerkinrigting op basis van die Dordtse KO van 1619 'n anakronisme geword. Daarmee word 'n stelsel wat plaaslike vryheid en verantwoordelikheid wil waarborg gelees en toegepas deur die bril van sentralisasie en monisme wat van alle pluralisme, verskeidenheid, plaaslike variasie, vryheid onder die Woord van God, wars is.

Opsomming van die beginsels en grondslag van Gereformeerde kerkinrigting van die 16de eeu

1. Die gemeente of plaaslike kerk as primêre natuurlike assosiatiewe korporasie is en bly in alle geledinge volledige regspersoonlikheid. Dit word nie opgelos en/of verplaas waar dit met ander kerke saamwerk t.o.v. gemeenskaplike belange nie. 
2. Die plaaslike kerk as gemeenskap is selfstandig en primêr verantwoordelik om homself te regeer. Binne die homogene en hegte gemeenskap kan die meerderheidstem regeer mits

(1) dit nie die enkeling se reg en vryheid aantas deur op hom verpligtinge te lê wat nie op die Skrif of ooreenkoms gegrond is nie; en

(2) dit nie met die reg in die Skrif, Belydenis of Kerkorde in stryd is nie. Die soewereiniteit van die reg waarborg die vryheid van die lidmaat en die gemeenskap.

3. Die regsoewereiniteit word op alle instrumente in die kerkregering van toepassing gemaak. Die ampsdraers moet hulle verbind om die reg (Skrif, Belydenis en Kerkorde) te alle tye te hand: haaf. Indien hulle versuim, word hulle metterdaad geskors (art. 53, 54 DKO).

4. Die plaaslike kerk gaan met die oog op bepaalde en gemeenskaplike belange met ander plaaslike kerke konfederale verbintenisse aan. Die konfederale liggaam verkry daarmee egter geen mag oor die sake van die kerk nie. Art. 30 DKO bepaal dat wat op die mindere afgehandel kan word, moet nie na die klassis of sinode gestuur word nie. Dit beklemtoon die soewereiniteit van elke gemeenskap oor sy eie belange.

5. Sekere belange van die plurale gemeenskappe kan ten beste gedien word in samewerking met ander selfstandige kerke. Die plaaslike kerke verloor egter nie hulle selfstandigheid wanneer hulle saam met ander kerke oor gemeenskaplike belange handel nie. Inteendeel, die samekomste behoort die lokale en plurale selfstandigheid te bevestig en te verstewig.

6. Die ,getrapte afvaardiging" erken en eerbiedig die plurale kerke as regspersone wat hulle selfstandigheid in en deur die samekoms met ander behou. Die plurale kerke bly subjekte in die besluitneming ter klassis of sinode. Die behoud van die natuurlike gemeenskap en sy reg om homself te bestuur en vryheid te handhaaf, staan lynreg teenoor die rewolusionêre gesagsbegrip dat (1) die kiesers hulle reg en mag deur verkiesing van hulle vervreem en na die sekondêre instansie delegeer; (2) dat die instansie daardeur self 'n „korporasie" soos die gemeente word; en (3) dat die meerderheid op kwantitatiewe grond soewerein is en die reg ook vir en oor minderhede bepaal. Die Gereformeerde beginsel is: stemme moet geweeg en nie getel word nie. Daarmee word die soewereiniteit van die reg en nie die kerklike struktuur nie as grond vir die vryheid en verantwoordelikheid vasgehou.

7. Die begrip vir die realiteit laat die 16de eeuse Kerkordes ook die natuurlike etniese verskeidenheid en pluraliteit waarborg. In 1571 word die Hollandse en Franse Geloofsbelydenis vir onderskeie groepe erken. Eenheid ten spyte van verskeidenheid word met buitelandse kerke as ' $n$ vorm van pluraliteit erken waarin een kerk nie sy opvattings aan 'n buitelandse oplê nie (art. $85 \mathrm{KO}$ ).

8. Die politieke en kerklike stelsels wat pluralisme teenoor monisme, desentralisasie teenoor sentralisasie in die 16de en 17de eeu erken, kan met vrug vandag opnuut onder oë gesien word vir 


\section{In die Skriflig}

die basis waarop 'n multi-nasionale werklikheid in Suidelike Afrika kan bestaan. Soos die politieke bestel die Kerkorde van 1619 help vorm het, kan die beginsels in die Geref. KO ook die huidige politieke bestel help ontwikkel. Die soewereiniteit van die reg i.p.v. dié van die parlement, die reg tot selfbeskikking en plaaslike vryheid en verantwoordelikheid, is die enigste basis waarop 'n vreedsame en gelukkige samelewing gebou kan word.

9. Vryheid kan alleen bestaan waar reg regeer. Tirannie kom na vore wanneer persone, groepe, korporasies of selfs kerke aan 'n ander voorskryf of daaroor heerskappy voer.

\section{SLOTSOM}

Die beginsel in art. $30 \mathrm{KO}$ gaan dus baie dieper as ' $\mathrm{n}$ formele aanduiding wat op 'n agenda mag kom. Dit wil nie die aard van agendastukke definieer nie, maar wil die regte en pligte van kerkvergaderings waarborg. Dit maak 'n Bybelse beginsel van hoe elkeen geroep is om aan die Here verantwoordelik te lewe en werk diensbaar in kerkvergaderings. Tegelykertyd wil dit negatief enige heerskappyvoering en magsindringing uitsluit sodat die kerke nie weer soos in die tyd van Christus of die Reformasie deur kerklike dienaars totaal onder 'n juk van diensbaarheid gebring word nie.

Pluralisme is net so waardevol as monisme (eenheid). Die verskeidenheid moet ook in eenheid tot eer van die Here na vore kom. Die bepalende norm is nie eenheid as enersheid nie, maar of die primaat van die Woord in die plurale en eenheid gewaarborg bly.

Ons moet art. 30 toepas in die kritiese besef dat ons in 'n tyd, land en omstandighede leef wat tradisioneel geweldig sterk deur die Engelse monisme beinvloed is. Gevolglik word „,independentisme" as 'n kerklike doodsonde en kollegialisme as 'n duldbare swakheid beskou. Ons mense sondig eerder in laasgenoemde as in eersgenoemde rigting.

\section{VERWYSINGS}

1 P. J. Loots, Pluralisme in Staat en Kerk, ongepubliseerde proefskrif, UK, 1962 , p. 66 h.a. Von Girke: Natural Law and theory of society. Vgl. ook A. H. Murray, Die Post St. Bartholomeusnag literatuur...., In die Skriflig, 1976 en B. Spoelstra, Plaaslike Vryheid en Verantwoordelikheid.... ACB-kongres, Die Calvinis se antwoord op meerderheidsregering, Potchefstroom, 1977.

2 Loots, a.w., p. iv, h.a. E. Baker.

3 F. L. Rutgers, De Geldigheid der Oude Kerkenordeningen, p 17; J. de Jong, De Voorbereiding en Konstituering van het kerkverband der Nederl. Kerken in de 16de eeu.

4 Loots, a.w. 173 h.a. Voetius Pol. Eccl. IV, p. 168.

5 Vgl F. E. O'Brien Geldenhuys, Die Regsposisie van die Kerkraad, Ring en Sinode, 1951, p. 156.

6 A. A. van Schelven, Nederl. Vlugtelingkerken, p. 128.

7 By Loots, a.w., p. 49.

8 Ibid., p 82 h.a. Figgus, Churches in the modern State. 